\title{
Hypoglycemia: A Possible Link between Insulin Resistance, Metabolic Dyslipidemia, and Heart and Kidney Disease (the Cardiorenal Syndrome)
}

\author{
Myriam Ensling $^{\mathrm{a}}$ William Steinmann $^{\mathrm{a}}$ Adam Whaley-Connell $^{\mathrm{b}, \mathrm{c}}$ \\ Divisions of a General Internal Medicine and ${ }^{\mathrm{b}}$ Nephrology and Hypertension, \\ Department of Internal Medicine, University of Missouri-Columbia School of Medicine, \\ and ${ }^{\mathrm{C} H a r r y}$ S. Truman VA Medical Center, Columbia, Mo., USA
}

\author{
Key Words \\ Cardiorenal syndrome $\cdot$ Dyslipidemia $\cdot$ Hypoglycemia $\cdot$ Insulin resistance $\cdot$ Non-esterified \\ fatty acids $\cdot$ Obesity
}

\begin{abstract}
Resistance to insulin metabolic signaling in adipose tissue contributes to the lipid abnormalities in obese, hyperinsulinemic, insulin-resistant patients who develop the cardiorenal syndrome. These same metabolic dyslipidemic abnormalities can be found in conditions of caloric energy restriction with decreased adiposity or normal insulin levels, such as anorexia, starvation or non-diabetic kidney disease. In this review, we assess hypoglycemia as an alternative physiological explanation for the biochemical and lipid findings in conditions of insulin resistance (IR). Therefore, PubMed databases (1961-2010) were searched for articles on the effect of hypoglycemia and starvation on non-esterified fatty acid (NEFA) elevation and abnormalities in insulin signaling in muscles as well as abnormal kidney metabolism. The search included articles on NEFA and their role in triglyceride (TG) and high-density lipoprotein (HDL) metabolism, as well as kidney and heart disease. Available studies support that hypoglycemia increases NEFA generation from adipose tissue. Elevated levels of NEFA induce increased plasma levels of TG and decreased levels of HDL cholesterol, and may cause direct kidney and myocardial damage. IR of adipose and skeletal muscle tissue, and the elevation in insulin levels in obese, insulin-resistant patients could be explained by an adaptation to their carbohydrate intake. These molecular abnormalities in insulin metabolic signaling can also be found in hypoglycemia or starvation. In conclusion, IR of adipose tissue cannot fully explain the lipid ab-
\end{abstract}




\section{CardioRenal Medicine}

normalities observed in the cardiorenal syndrome. Decreased blood glucose levels (e.g. hypoglycemia) occur frequently in patients at risk for this syndrome. Hypoglycemia-induced increases in NEFA levels can promote lipid abnormalities that contribute to IR and the cardiorenal syndrome.

Copyright $\odot 2011$ S. Karger AG, Basel

\section{Introduction}

Insulin resistance (IR) has been described as a condition wherein circulating levels of insulin are inadequate to elicit a metabolic response from adipose tissue, skeletal muscle and liver cells as well as other non-traditional insulin-sensitive tissues, such as cardiovascular and kidney tissue. IR is characterized by the presence of elevated levels of insulin (e.g. hyperinsulinemia), impaired glucose tolerance, overweight or obesity, hypertension, and microalbuminuria [1]. These metabolic and hemodynamic abnormalities have been collectively referred to as the metabolic syndrome, and - in association with renal disease - as the cardiorenal syndrome. This syndrome includes a cluster of lipid abnormalities including low fasting high-density lipoprotein (HDL) cholesterol, increased small low-density lipoprotein (LDL) particles and elevated triglyceride (TG) levels. These abnormalities represent a combination of overproduction of very low-density lipoprotein (VLDL) and an increased catabolism of (HDL) apolipoprotein (Apo) A-I particles [2,3] known to increase the risk for heart and kidney disease (i.e. the cardiorenal syndrome) $[4,5]$.

The lipid abnormalities in the cardiorenal syndrome are, in part, the result of resistance of adipose tissue to the action of insulin [1]. Elevated free non-esterified fatty acids (NEFA) have been found to counteract the metabolic action of insulin and are considered to be a factor contributing to the development of IR and associated metabolic abnormalities [6]. Interestingly, there are similarities between the metabolic changes found in IR and the pattern of changes found in other unrelated chronic disease states. These IR-associated disease states include conditions under which insulin levels are usually low or not elevated, e.g. in type 1 diabetes [6], advanced stages of chronic kidney disease [5, 8], and starvation [9-11]. Further, IR is also seen in conditions where body fat is often low, including congenital lipodystrophies [12], anorexia nervosa [13], and chronic stress conditions [14].

Herein, we review the phenomena of lipid abnormalities and IR found in obesity and diabetes as well as conditions such as caloric restriction, kidney disease and the cardiorenal syndrome. Observations of IR and metabolic dyslipidemia in disparate medical conditions suggest that the presence of low glucose levels may be a viable alternative explanation for the occurrence of metabolic dyslipidemia.

\section{Hypoglycemia Promotes NEFA Elevations}

Hypoglycemia is a potentially fatal condition that frequently occurs in type 1 and 2 diabetes $[15,16]$, but evidence regarding incident hypoglycemia in non-diabetics is somewhat limited. However, there are some data that suggest nocturnal decreases in glucose levels are a common phenomenon even in non-diabetics, evoking a dipping status for glycemia. Studies of glucose levels using continuous glucose monitoring in normal subjects during REM sleep have demonstrated drops in glucose levels of about $6 \mathrm{mg} / \mathrm{dl}(5 \%)$ in normal- and overweight subjects [17].

Studies evaluating blood glucose patterns and appetite in animals as well as healthy humans have demonstrated that blood glucose is highly controlled and capable of self-regula- 


\section{CardioRenal \\ Medicine}

\begin{tabular}{l|l}
\hline \multicolumn{2}{l}{ Cardiorenal Med 2011;1:67-74 } \\
\hline DOI: 10.1159/000322886 & $\begin{array}{l}\text { @ 2011 S. Karger AG, Basel } \\
\text { www.karger.com/crm }\end{array}$ \\
Published online: January 17, 2011 &
\end{tabular}

Ensling et al.: Hypoglycemia and the Cardiorenal Syndrome

tion. Research on appetite, starvation, and acute hypoglycemia suggests that compensatory mechanisms are activated in the presence of reductions in blood glucose levels into the hypoglycemic range [18]. A brief fall and rise in blood glucose of $6 \%$ from baseline occurs about 6 min before meal initiation [18]. It is thought that these transient declines have a stronger effect on food-seeking behavior than the absolute blood glucose concentration. In this regard, transient blood glucose concentrations that trigger food-seeking behavior occur at around $75-99 \mathrm{mg} / \mathrm{dl}$ in humans $[9,18]$. An analysis of plasma substrates preceding meal initiation in rats demonstrates a rise in NEFA $\sim 6$ min before meal initiation, which coincides with the nadir of the transient decline in blood glucose [9]. NEFA elevation represents an important mechanism for the reconciliation of energy balance during starvation in normal as well as obese subjects $[9,10]$. Studies on the effect of starvation on normal individuals and untreated type 2 diabetic patients support a greater decrease in blood glucose levels in diabetic individuals (17 vs. $6 \%$, respectively) after $5 \mathrm{~h}$ of starvation [10], with a simultaneous increase in NEFA and TG levels in diabetic patients. Other studies of starvation comparing healthy individuals and type 2 diabetic patients demonstrate a significant decrease in blood glucose of 7 and 23\%, respectively, with reciprocal increases in TG and NEFA [11]. These data implicate both transient declines in blood glucose levels and associated rises in NEFA as triggers of counter-regulatory mechanisms, including the drive for food ingestion.

There has also been interest in the relative impact of starvation on lipid kinetics in lean and obese subjects. Recent research supports the notion that obese individuals have a higher baseline lipolytic rate and an increased release of NEFA during starvation than lean individuals [19]. Further, studies on insulin-induced hypoglycemia reinforce the concept that NEFA levels decrease initially, reaching a nadir at $30 \mathrm{~min}$ that lasts about $90 \mathrm{~min}$, and then increase parallel to enhanced catecholamine release [20-24]. It appears that blood glucose levels that elicit counter-regulatory hormone release are slightly higher in obese than lean persons. These findings suggest the concept that glucose counter-regulatory systems are involved in the prevention, as well as the correction, of hypoglycemia. Further, activation of these systems at higher levels of blood glucose may contribute to enhanced NEFA release as it relates to obesity-related IR and dyslipidemia in the cardiorenal syndrome [20].

Even after restoration of euglycemia, enhanced adipose tissue lipolysis exerts long-lasting effects by blunting insulin metabolic actions in numerous tissues [24]. Hypoglycemia promotes a period of IR of 7-9 $\mathrm{h}$ where there is reduced insulin action [25]. Additional data further support the fact that acute IR episodes can last up to $18 \mathrm{~h}$ after two brief episodes of antecedent hypoglycemia [26]. These effects are induced primarily by counter-regulatory hormones, initially by increased levels of epinephrine and later by elevated levels of growth hormone and cortisol $[24,25]$. These hormones act indirectly by activating lipolysis, and by lipolysis-independent mechanism, with resulting increases in endogenous glucose production, suppression of peripheral glucose utilization, and increased oxidation of glucose and lipids [24].

These data collectively support the notion that hypoglycemia is a common phenomenon underrecognized in obese IR patients at high risk of developing the cardiorenal syndrome. Even modest drops in glucose levels can trigger counter-regulation of hypoglycemia that involves catecholamine release, elevation of NEFA and increased IR.

\section{NEFA Promote Increased TG and Decreased HDL Levels}

After a meal, adipose tissue removes TG particles from chylomicrons in the circulation. Lipoprotein lipase (LPL), located in the capillaries of adipose tissue, catalyzes the hydrolysis of TG from chylomicrons and from VLDL to release NEFA and glycerol, which are then 


\section{CardioRenal \\ Medicine}

\begin{tabular}{l|l}
\hline \multicolumn{2}{l}{ Cardiorenal Med 2011;1:67-74 } \\
\hline DOI: 10.1159/000322886 & $\begin{array}{l}\text { @ 2011 S. Karger AG, Basel } \\
\text { www.karger.com/crm }\end{array}$ \\
Published online: January 17, 2011 &
\end{tabular}

Ensling et al.: Hypoglycemia and the Cardiorenal Syndrome

stored as TG in adipose tissue [27]. Chylomicrons and endogenous TG-rich VLDL are mixed in blood and compete for LPL for TG removal. LPL-mediated removal of TG particles is limited because it is dependent on a saturation mechanism [28]. Endogenous TG-rich lipoproteins accumulate in the human plasma after oral fat intake [29]. Insulin promotes the transfer of LPL synthesized in adipocytes to adipose tissue endothelial cells, a mechanism inhibited by epinephrine and norepinephrine [30]. LPL is then eventually released into the circulation.

In adipose tissue, endothelial cell LPL activity increases with feeding and declines in the fasting state, while in other tissues, such as cardiac muscles, it increases during fasting or starvation. During fasting, as circulating concentrations of chylomicrons decline, adipose tissue begins to release its stored triglycerides. This process is accomplished by lipases that are distinct from LPL and are found within the adipocytes. The major lipase involved is the hormonesensitive lipase. It is activated in the fasting state by the action of glucagon and catecholamines, actions ultimately opposed by insulin. Due to the action of hormone-sensitive lipase on adipose tissue, glycerol and NEFA are released into the circulation and utilized as energy source by most tissues. A substantial fraction of NEFA will undergo esterification in the liver with the synthesis of TG, a more stable and less toxic form of circulating lipids [31-34].

Plasma NEFA are considered to be the major source of VLDL-TG [35]. In humans, acute elevations in plasma NEFA stimulate VLDL production. The most accepted model for fasting hypertriglyceridemia invokes the overproduction of VLDL as a result of increased rates of lipolysis and free fatty acid (NEFA) flux into the liver [35]. VLDL becomes activated after ApoC-II and ApoE incorporation into HDL. Activated VLDL are stripped from TG due to the action of the LPL especially in the muscles, most notably in the cardiac muscle.

The lipid abnormalities observed in obese IR individuals include low levels of ApoA-I, the characteristic component of HDL. NEFA have been found to influence the metabolism of HDL, especially regarding the catabolism of ApoA-I. IR studies have shown that the presence of hepatic overproduction of VLDL together with decreased LPL activity result in expansion of the VLDL-TG pool and enhancement of cholesteryl ester transfer protein-mediated hetero-exchange of neutral lipids among lipoproteins. This leads to increases in HDLTG concentrations. Subsequent hydrolysis by hepatic lipase results in unstable HDL ApoA-I particles, which are rapidly cleared from the plasma [36].

Some studies have demonstrated that variation in VLDL-ApoB production, and hence plasma TG concentration, exerts a major effect on the catabolism of HDL-ApoA-I [37]. Isotopic studies found that obese IR subjects have a markedly increased fractional catabolic rate of ApoA-I and, to a lesser extent, increased ApoA-I production, accounting for a net lowering of plasma HDL-ApoA-I concentrations [38]. Other authors have demonstrated that hypercatabolism of ApoA-I has a dominant effect on HDL concentration in patients with obesity and IR [36]. Animal and human kinetic studies have shown that enhanced HDL-ApoAI clearance is directly dependent on the TG enrichment of HDL and on the activity of hepatic lipase [39].

In summary, elevated plasma NEFA seems to be a key element causing elevated TG and VLDL as well as decreased HDL levels, a lipid pattern associated with obesity, IR and the development of the cardiorenal syndrome.

\section{Role of Hypoglycemia in IR}

There is increasing interest regarding the development of lipid abnormalities in obese patients as it relates to IR and the development of the cardiorenal syndrome. Many of the molecular signaling abnormalities of lipid and glucose metabolism found in IR are similar 


\section{CardioRenal \\ Medicine}

\begin{tabular}{l|l}
\hline Cardiorenal Med 2011;1:67-74 \\
\hline DOI: 10.1159/000322886 & $\begin{array}{l}\text { @ } 2011 \text { S. Karger AG, Basel } \\
\text { www.karger.com/crm }\end{array}$ \\
\hline Published online: January 17, 2011 &
\end{tabular}

Ensling et al.: Hypoglycemia and the Cardiorenal Syndrome

to those observed during starvation or hypoglycemia. Coupled with increased NEFA levels, these signaling abnormalities have been shown to promote cardiovascular and kidney disease.

\section{Effects of Hypoglycemia on Skeletal Muscles}

In skeletal muscles, intracellular glucose phosphorylation is impaired in hypoglycemia as well as more classical IR states. In this regard, there are reductions in hexokinase II activity in starvation as well as obesity and type 2 diabetes [40, 41]. Furthermore, abnormalities in glycogen synthesis with decreased glycogen synthase and phosphofructose kinase activity in muscles have been found during episodes of hypoglycemia as well as IR [42, 43]. Interestingly, recent data suggest that during hypoglycemia skeletal muscle glycogen synthase activity is decreased in diabetics compared to controls [43]. Whether diabetic patients with decreased glycogen synthase activity adapt to repeated episodes of hypoglycemia has yet to be clarified. These data indicate that the counter-regulatory responses to hypoglycemia may be similar in chronic catabolic states and in diabetes.

\section{Role of NEFA in Mitochondrial Dysfunction}

The role of mitochondrial dysfunction in IR is currently receiving intense attention as a link between cardiac and renal disease [44]. One unifying concept is the Randle cycle or the competition between glucose and NEFA for oxidation in the mitochondria. NEFA oxidation increases the mitochondrial membrane potential $(\Delta \Psi)$ with the proton leak, causing reversed electron flow and the production of reactive oxygen species. Thereby, overloading the system with both substrates (NEFA and glucose) contributes to mitochondrial damage (glucose toxicity) [45]. Therefore, it would be expected that several physiological mechanisms should be in place to prevent the entrance of glucose into the cell while there is increased availability of NEFA, as during hypoglycemia.

\section{Insulin Levels and Carbohydrate Intake}

Elevation of fasting as well as postprandial insulin levels is common in IR [46-48]. The assumption is that insulin levels increase to adapt to resistance to insulin metabolic signaling in adipose, liver and skeletal muscle tissue. Yet, there is evidence to suggest that the threshold of resistance to insulin in those tissues is relatively low and this resistance is probably overcome by increased postprandial insulin secretion [7]. It should be noted that insulin secretion can adapt to carbohydrate and protein intake. Pancreatic $\beta$-cells have the capacity to adapt insulin secretion to increases or decreases in carbohydrate intake [48]. A significant increase in $\beta$-cell proliferation after $48 \mathrm{~h}$ of glucose/insulin infusion has been demonstrated in rats [47]. This has been referred to as $\beta$-cell mass plasticity.

Procedures to evaluate systemic IR or $\beta$-cell function include the euglycemic, hyperinsulinemic clamp or the hyperglycemic clamp, and have been used extensively. It is reasonable to speculate that patients with baseline hyperinsulinemia are exposed to a larger total amount of insulin than controls when subjected to this test, especially when the insulin dose given is not based on lean weight. The measurements and correction of glucose levels in the clamp are performed every 5-10 min. Since physiological drops and rises in blood glucose occur spontaneously, and these changes can present in a shorter time frame than those in the clamp procedure $[9,18]$, there is a possibility that the clamp methodology is insensitive to detect short-lived blood glucose drops. The regulatory mechanisms in hypoglycemia are triggered more by changes in glucose than the specific glucose level. Therefore, adaptive mechanisms can be elicited at glucose levels that could be perceived within an acceptable range by the researchers. Furthermore, the test itself could promote resistance to insulin action by causing drops in blood glucose levels that are immediately compensated by increases in NEFA which promotes IR. 


\section{CardioRenal \\ Medicine}

\begin{tabular}{l|l}
\hline Cardiorenal Med 2011;1:67-74 \\
\hline DOI: 10.1159/000322886 & $\begin{array}{l}\text { @ 2011 S. Karger AG, Basel } \\
\text { www.karger.com/crm }\end{array}$ \\
\hline Published online: January 17, 2011 &
\end{tabular}

Ensling et al.: Hypoglycemia and the Cardiorenal Syndrome

\section{NEFA Cause Direct Tissue Damage Including Myocardial and Kidney Disease}

NEFA are known to contribute to lipid accumulation in several non-adipose tissues, including cardiac and kidney tissue, a phenomenon referred to as lipotoxicity. In the heart, myocardial lipotoxicity has been described in association with metabolic cardiomyopathy [49]. Additionally, increased circulating NEFA have been shown to have a pro-arrhythmic effect [50] and to be an independent risk factor for sudden death in middle-aged men free of known cardiovascular disease [51].

There is an established relationship between obesity, IR and albuminuria and kidney disease [52]. NEFA are bound to albumin and are normally filtered through the glomerular filtration barrier and then reabsorbed by the proximal tubules. In the presence of proteinuria, NEFA overload and deposition may occur at the level of the proximal tubule cell. This deposition of free fatty acids (NEFA) induces inflammation and apoptosis causing podocyte and proximal tubular damage [53]. Liver-type fatty acid binding protein (L-FABP) is a cytoplasmic protein that belongs to a group of molecules that participate in intracellular fatty acid metabolism. In the presence of NEFA overload, there is an up-regulation of L-FABP in proximal tubules, and this apparently represents a protective mechanism to reduce tubular damage [54]. Urinary excretion of L-FABP has been found to be correlated with the severity and progression of diabetic kidney disease [54].

Compared to other forms of primary kidney disease, there are higher levels of urinary NEFA in patients with diabetic kidney disease. In this regard, the degree of urinary secretion of NEFA is strongly correlated with the degree of tubulointerstitial damage. The levels of urinary L-FABP were also significantly higher in those with diabetic kidney disease. These results indicate that diabetic patients may be exposed to NEFA overload in the proximal tubules, and this overload contributes to diabetic renal disease [54]. Further research is necessary, in particular on the reason for tubular NEFA overload in diabetic patients and whether this is related to repeated episodes of hypoglycemia.

\section{Conclusions}

Inordinate decreases in blood glucose levels appear to be more common in patients at risk for IR. Hypoglycemia may, in turn, promote elevations in NEFA, TG, and LDL levels, decreases in HDL levels, as well as other related biochemical and mitochondrial abnormalities in insulin-sensitive tissue, including the heart and kidney. While these abnormalities have been attributed to a primary resistance to insulin metabolic actions, the possibility that hypoglycemia is a primary instigator of these changes has not been adequately explored. IR has been described in conditions not related to obesity or diabetes, such as starvation, malnutrition, chronic renal failure or lipodystrophies, where insulin levels may be normal or low. Again, repeated episodes of hypoglycemia could explain the presence of IR and lipid abnormalities found in these conditions. Counteracting the metabolic actions of insulin could be part of a physiological survival mechanism during hypoglycemia. The elevations in NEFA during acute hypoglycemia could provide an immediate source of energy supply for most tissues, including the myocardium, that over time are detrimental to not only the heart but the kidney as well. It is likely that the occurrence of significant nocturnal drops in glucose in obese patients with elevated insulin levels at baseline contribute to their lipid abnormalities and worsening IR. Additional preclinical and clinical research regarding hypoglycemia in the development of lipid abnormalities in IR, as well as the link between elements of cardiorenal disease, is needed. 


\section{CardioRenal Medicine}

\begin{tabular}{|c|c|}
\hline al Med 2011;1:67-74 & \\
\hline $\begin{array}{l}\text { DOI: } 10.1159 / 000322886 \\
\text { Published online: January 17, } 2011\end{array}$ & $\begin{array}{l}\text { (c) } 2011 \text { S. Karger AG, Basel } \\
\text { www.karger.com/crm }\end{array}$ \\
\hline
\end{tabular}

Ensling et al.: Hypoglycemia and the Cardiorenal Syndrome

\section{Disclosure Statement}

Dr. Whaley-Connell is funded by the Department of Veteran's Affairs (Career Development Award-2).

\section{References}

1 Whaley-Connell A, Sowers JR: Hypertension and insulin resistance. Hypertension 2009;54:462-464.

-2 Adiels M, Olofsson SO, Taskinen MR, Boren J: Overproduction of very low-density lipoproteins is the hallmark of the dyslipidemia in the metabolic syndrome. Arterioscler Thromb Vasc Biol 2008;28:1225-1236.

-3 Chan DC, Watts GF, Redgrave TG, Mori TA, Barrett PH: Apolipoprotein B-100 kinetics in visceral obesity: associations with plasma apolipoprotein C-III concentration. Metabolism 2002;51:1041-1046.

-4 Rydén L, Standl E, Bartnik M, Van den Berghe G, Betteridge J, de Boer MJ, Cosentino F, Jönsson B, Laakso M, Malmberg K, Priori S, Ostergren J, Tuomilehto J, Thrainsdottir I, Vanhorebeek I, Stramba-Badiale M, Lindgren P, Qiao Q, Priori SG, Blanc JJ, Budaj A, Camm J, Dean V, Deckers J, Dickstein K, Lekakis J, McGregor K, Metra M, Morais J, Osterspey A, Tamargo J, Zamorano JL, Deckers JW, Bertrand M, Charbonnel B, Erdmann E, Ferrannini E, Flyvbjerg A, Gohlke H, Juanatey JR, Graham I, Monteiro PF, Parhofer K, Pyörälä K, Raz I, Schernthaner G, Volpe M, Wood D, Task Force on Diabetes and Cardiovascular Diseases of the European Society of Cardiology (ESC), European Association for the Study of Diabetes (EASD): Guidelines on diabetes, pre-diabetes, and cardiovascular diseases: executive summary. The Task Force on Diabetes and Cardiovascular Diseases of the European Society of Cardiology (ESC) and of the European Association for the Study of Diabetes (EASD). Eur Heart J 2007;28:88-136.

5 Sowers JR: Metabolic risk factors and renal disease. Kidney Int 2007;71:719-720.

6 Roden M, Price TB, Perseghin G, Petersen KF, Rothman DL, Cline GW, Shulman GI: Mechanism of free fatty acidinduced insulin resistance in humans. J Clin Invest 1996;97:2859-2865.

7 Ferrannini E, Natali A, Bell P, Cavallo-Perin P, Lalic N, Mingrone G: Insulin resistance and hypersecretion in obesity. J Clin Invest 1997;100:1166-1173.

-8 Ikee R, Hamasaki Y, Oka M, Maesato K, Mano T, Moriya H, Ohtake T, Kobayashi S: Glucose metabolism, insulin resistance, and renal pathology in non-diabetic chronic renal disease. Nephron Clin Pract 2008;108:c163-c168.

-9 Campfield LA, Smith FJ: Blood glucose dynamics and control of meal initiation: a pattern detection and recognition theory. Physiol Rev 2003;83:25-58.

10 Gannon MC, Nuttall FQ, Lane JT, Fang S, Gupta V, Sandhofer CR: Effect of 24 h starvation on plasma glucose and insulin concentrations in subjects with untreated non-insulin-dependent diabetes mellitus. Metabolism 1996;45:492-497.

11 Groop LC, Bonadonna R, DelPrato S, Ratheiser K, DeFronzo RA: Effect of prolonged overnight fasting on energy metabolism in non-insulin dependent diabetic and non-diabetic subjects. Acta Endocrinol (Copenh) 1990;123:30-36.

12 Hegele RA: Familial partial lipodystrophy: a monogenic form of the insulin resistance syndrome. Mol Genet Metab 2000;71:539-544.

13 Ohwada R, Hotta M, Oikawa S, Takano K: Etiology of hypercholesterolemia in patients with anorexia nervosa. Int J Eat Disord 2006;39:598-601.

14 Branth S, Ronquist G, Stridsberg M, Hambraeus L, Kindgren E, Olsson R, Carlander D, Arnetz B: Development of abdominal fat and incipient metabolic syndrome in young healthy men exposed to long-term stress. Nutr Metab Cardiovasc Dis 2007;17:427-435.

15 Barnard K, Thomas S, Royle P, Noyes K, Waugh N: Fear of hypoglycaemia in parents of young children with type 1 diabetes: a systematic review. BMC Pediatr 2010;10:50.

16 Amiel SA, Dixon T, Mann R, Jameson K: Hypoglycaemia in type 2 diabetes. Diabet Med 2008;25:245-254.

17 Bialasiewicz P, Pawlowski M, Nowak D, Loba J, Czupryniak L: Decreasing concentration of interstitial glucose in REM sleep in subjects with normal glucose tolerance. Diabet Med 2009;26:339-344.

18 Campfield LA, Smith FJ: Transient declines in blood glucose signal meal initiation. Int J Obesity 1990;14(suppl 3):1533.

19 Mittendorfer B, Magkos F, Fabbrini E, Mohammed BS, Klein S: Relationship between body fat mass and free fatty acid kinetics in men and women. Obesity 2009;17:1872-1877.

20 Schwartz NS, Clutter WE, Shah SD, Cryer PE: Glycemic thresholds for activation of glucose counterregulatory systems are higher than the threshold for symptoms. J Clin Invest 1987;79:777-781.

-21 Caprio S, Gelfand R, Tamborlane WV, Sherwin RS: Oxidative fuel metabolism during mild hypoglycemia: critical role of free fatty acids. Am J Physiol 1989;256(3 pt 1):E413-E419.

22 Shamoon H, Friedman S, Canton C, Zacharowicz L, Hu M, Rossetti L: Increased epinephrine and skeletal muscle responses to hypoglycemia in non-insulin dependent diabetes mellitus. J Clin Invest 1994;93:2562-2571.

23 Fanelli CG, De Feo P, Porcellati F, Perriello G, Torlone E, Santeusanio F, Brunetti P, Bolli GB: Adrenergic mechanisms contribute to the late phase of hypoglycemic glucose counterregulation in humans by stimulating lipolysis. J Clin Invest 1992;89:2005-2013.

24 Lucidi P, Rossetti P, Porcellati F, Pampanelli S, Candeloro P, Andreoli AM, Perriello G, Bolli GB, Fanelli CG: Mechanisms of insulin resistance following insulin-induced hypoglycemia in humans: the role of lipolysis. Diabetes 2010; 59:1349-1357. 


\section{CardioRenal Medicine}

\begin{tabular}{l|l}
\hline Cardiorenal Med 2011;1:67-74 \\
\hline $\begin{array}{l}\text { DOI: 10.1159/000322886 } \\
\text { Published online: January 17, } 2011\end{array}$ & $\begin{array}{l}\text { @ 2011 S. Karger AG, Basel } \\
\text { www.karger.com/crm }\end{array}$ \\
\hline
\end{tabular}

Ensling et al.: Hypoglycemia and the Cardiorenal Syndrome

25 Fowelin J, Atvall S, von Schenck H, Smith U, Lager I: Combined effect of growth hormone and cortisol on late posthypoglycemic insulin resistance in humans. Diabetes 1989;38:1357-1364.

-26 Heller SR, Cryer PE: Reduced neuroendocrine and symptomatic responses to subsequent hypoglycemia after 1 episode of hypoglycemia in non-diabetic humans. Diabetes 1991;40:223-226.

27 Fielding BA, Frayn KN: Lipoprotein lipase and the disposition of dietary fatty acids. Br J Nutr 1998;80:495-502.

28 Brunzell JD, Hazzard WR, Porte D, Bierman EL: Evidence for a common, saturable, triglyceride removal mechanism for chylomicrons and very low density lipoproteins in man. J Clin Invest 1973;52:1578-1585.

-29 Karpe F, Steiner G, Olivecrona T, Carlson LA, Hamsten A: Metabolism of triglyceride-rich lipoproteins during alimentary lipemia. J Clin Invest 1993;91:748-759.

30 Jensen MD, Haymond MW, Gerich JE, Cryer PE, Miles JM: Lipolysis during fasting. Decreased suppression by insulin and increased stimulation by epinephrine. J Clin Invest 1987;79:207-213.

- 31 Gibbons GF, Wiggins D, Brown AM, Hebbachi AM: Synthesis and function of hepatic very-low-density lipoprotein. Biochem Soc Trans 2004;32(pt 1):59-64.

32 Elabbadi N, Day CP, Virden R, Yeaman SJ: Regulation of phosphatidic acid phosphohydrolase 1 by fatty acids. Lipids 2002;37:69-73.

-33 Carman GM, Han GS: Roles of phosphatidate phosphatase enzymes in lipid metabolism. Trends Biochem Sci 2006; 31:694-699.

-34 Parks E, Krauss R, Christiansen MP, Neese RA, Hellerstein MK: Effects of a low-fat, high-carbohydrate diet on VLDLtriglyceride assembly, production, and clearance. J Clin Invest 1999;104:1087-1096.

- 35 Lewis GF, Uffelman KD, Szeto LW, Weller B, Steiner G: Interaction between free fatty acids and insulin in the acute control of very low density lipoprotein production in humans. J Clin Invest 1995;95:158-166.

-36 Rashid S, Watanabe T, Sakaue T, Lewis GF: Mechanisms of HDL lowering in insulin resistant, hypertriglyceridemic states: the combined effect of HDL triglyceride enrichment and elevated hepatic lipase activity. Clin Biochem 2003; 36:421-429.

37 Chan DC, Barrett PHR, Ooi EMM, Ji J, Chan DT, Watts GF: Very low density lipoprotein metabolism and plasma adiponectin as predictors of high-density lipoprotein apolipoprotein A-I kinetics in obese and nonobese men. J Clin Endocrinol Metab 2009;94:989-997.

- 38 Brinton EA, Eisenberg S, Breslow JL: Increased apo A-I and apo A-II fractional catabolic rate in patients with low high density lipoprotein-cholesterol levels with or without hypertriglyceridemia. J Clin Invest 1991;87:536-544.

-39 Rashid S, Barrett PH, Uffelman KD, Watanabe T, Adeli K, Lewis GF: Lipolytically modified triglyceride-enriched HDLs are rapidly cleared from the circulation. Arterioscler Thromb Vasc Biol 2002;22:483-487.

-40 Pendergrass M, Koval J, Vogt C, Yki-Jarvinen H, Iozzo P, Pipek R, Ardehali H, Printz R, Granner D, DeFronzo RA, Mandarino LJ: Insulin-induced hexokinase II expression is reduced in obesity and NIDDM. Diabetes 1998;47:387384.

- 41 Tsintzas K, Jewell K, Kamran M, Laithwaite D, Boonsong T, Littlewood J, Macdonald I, Bennett A: Differential regulation of metabolic genes in skeletal muscle during starvation and refeeding in humans. J Physiol 2006;575(pt 1):291303.

42 Henriksen EJ: Deregulation of glycogen synthase kinase-3 in skeletal muscle and the etiology of insulin resistance and type 2 diabetes. Curr Diabetes Rev 2010;6:285-293.

$\checkmark 43$ Orskov L, Bak JF, Abildgard, Schmitz O, Andreasen F, Richter EA, Skjaebaek C, Moller N: Inhibition of muscle glycogen synthase activity and non-oxidative glucose disposal during hypoglycemia in normal man. Diabetologia 1996; 39:226-234.

Kim JA, Wei Y, Sowers JR: Role of mitochondrial dysfunction in insulin resistance. Circ Res 2008;102:401-414.

45 Hue L, Taegtmeyer H: The Randle cycle revisited: a new head for an old hat. Am J Physiol Endocrinol Metab 2009; 297:E578-E591.

46 Polonsky KS, Given BD, Hirsch L, Shapiro ET, Tillil H, Beebe C, Galloway JA, Frank BH, Karrison T, Van Cauter E: Quantitative study of insulin secretion and clearance in normal and obese subjects. J Clin Invest 1988;81:435-441.

-47 Paris M, Bernard-Kargar C, Berthault MF, Bouwens L, Ktorza A: Specific and combined effects of insulin and glucose on functional pancreatic B-cell mass in vivo in adult rats. Endocrinology 2003;144:2717-2727.

48 Bonner-Weir S, Deery D, Leahy JL, Weir GC: Compensatory growth of pancreatic $\beta$-cells in adult rats after short-term glucose infusion. Diabetes 1989;38:49-53.

49 Boudina S, Abel ED: Diabetic cardiomyopathy, causes and effects. Rev Endocr Metab Disord 2010;11:31-39.

50 Oliver MF, Opie LH: Effects of glucose and fatty acids on myocardial ischaemia and arrhythmias. Lancet 1994;343: $155-158$.

51 Jouven X, Charles MA, Desnos M, Ducimetiere P: Circulating nonesterified fatty acid levels as a predictive risk factor for sudden death in the population. Circulation 2001;104:756-761.

52 Hsu CY, McCulloch CE, Iribarran C, Darbinian J, Go AS: Body mass index and risk for end-stage renal disease. Ann Intern Med 2006;144:21-28.

53 Thomas ME, Harris KP, Walls J, Furness PH, Brunskill NJ: Fatty acids exacerbate tubulointerstitial injury in proteinoverload proteinuria. Am J Physiol Renal Physiol 2002;283:F640-F647.

54 Sasaki H, Kamijo-Ikemori A, Sugaya T: Urinary fatty acids and liver-type fatty acid binding protein in diabetic nephropathy. Nephron Clin Pract 2009;112:c148-c156. 